$\mathbb{T}$ periodica polytechnica

Chemical Engineering $52 / 2(2008) 5760$

doi: 10.3311/pp.ch.2008-2.02

web: http://www.pp.bme.hu/ch

(c) Periodica Polytechnica 2008

RESEARCH ARTICLE

\section{Reduction of fluoride and sulfate ions in Syrian phosphoric acid by extraction with tertiary amins}

Mohamed Alkhaled Abdulbake

Received 2008-07-07

\begin{abstract}
General Fertilizer Company GFC Homs produces a lot of wet phosphoric acid, but it is unsuitable for food or pharmaceutical uses. Reduction of fluoride and sulfate ions contents in wet phosphoric acid by liquid - liquid extraction with tertiary aliphatic amins was studied. The effect of solvent concentration and temperature on the extraction was studied. The effect of diluent on the extraction yield and raffinate acid specifications was also studied.
\end{abstract}

\section{Keywords}

amins $\cdot$ phosphoric acid $\cdot$ extraction $\cdot$ fluoride $\cdot$ sulfate

\section{Acknowledgement}

The authors would like to express their thanks and appreciation to the General Director of the Atomic Energy Commission Dr Ibrahim Othman for his help and encouragement to carry out this research.

\section{Mohamed Alkhaled Abdulbake}

Atomic Energy Commission, Hydrometallurgy Office, P.O.Box 6091 Damascus, Syria

e-mail: scientific@aec.org.sy

\section{Introduction}

There has been a wide interest over the last few years to develop a process to purify commercial wet phosphoric acid to obtain a pure acid. Most of the works are still in the developmental stage. Wet phosphoric acid contains 1 to $2 \%$ wt fluoride and about $2 \%$ sulfate that makes this acid unsuitable for food or pharmaceutical uses.

R. Baidoun et al [1] stated that fluoride reduction can be achieved to be about $97 \%$ using silica-gel under different conditions of pressure and temperature. In other works, processes for defluorination and purification of wet phosphoric acid were described. Partially immiscible organic solvents such as ethers, alcohols and amins were used [2-4]. Other investigators [5] reported the conditions for the fluoride removal from wet phosphoric acid by precipitation with sodium carbonate, sodium sulfate, potassium carbonate and potassium sulfate. MEAB report [6] describes a process to precipitate sulfate in wet phosphoric acid by adding barium carbonate. The efficiency of precipitation increases by increasing barium carbonate concentration and temperature. Canadian patent [7] claims the method of extracting fluoride and sulphate from an aqueous solution containing the fluoride. Ahron Eyal et al [8] stated the Defluorination of WPA to feed grade level can be achieved by extraction by amine with acids of low Al content. In earlier papers [9, 10]. We have studied the precipitation the sulfate ions from wet phosphoric acid using barium carbonate and we have studied the investigation of the synergistic effect of some alcohols on the extraction of phosphoric acid by TBP. The extraction of fluoride, sulfate, by these reagents is relatively small. Khorfan [10] found the extraction of $\mathrm{H}_{3} \mathrm{PO}_{4}$ by alcohols is selective and the extraction of heavy metals is negligible while that for iron and fluoride is small. Mousa [11] investigated the extraction yield of phosphoric acid after the addition of an optimized amount of some mineral acids.

\section{Experimental}

\subsection{Materials}

Tributylamin 99\%, trioctylamin (DEE) $93 \%$ and tridodecylamin $95 \%$ from Merck were used . A commercial wet phos- 
phoric acid $29 \%$ wt. $\mathrm{P}_{2} \mathrm{O}_{5}$ and a density of $1.28 \mathrm{~g} / \mathrm{cm}^{3}$ and containing $65 \mathrm{ppm}$ uranium as supplied from the General Fertilizer Company GFC Homs/Syria were used after being treated from solids and organic. Kerosene (flash point $76{ }^{0} \mathrm{C}-<5 \%$ aromatics - $3 \mathrm{mg} / \mathrm{kg}$ sulfur) as supplied from Pemco Chemical Co. was used as inert diluent.

\subsection{Apparatus and procedures}

Extraction was carried out in a beaker with a magnetic stirrer placed in a thermostat to control the temperature. The aqueous and organic phases were stirred for 5 minutes and were allowed 20 minutes to separate in a funnel. The concentrations of sulfate and chloride in the aqueous phase were determined by ion chromatography model Metrohm 792 basic IC. The concentration fluoride was determined by ion selective electrode model Metrohm 692 pH/Ion Meter. The concentration of the acid was measured by a potentiometric titration with $0.1 \mathrm{NaOH}$. The potentiometer type of E536 from Metrohm Co. was used. The concentration of sulfate and fluoride in the solvent was calculated from material balance. The yield was calculated from the equation:

Yield $\mathrm{Y} \%=\{$ mass $[\mathrm{X}]$ feed acid - mass $[\mathrm{X}]$ raffinate $\}$ /mass[X] feed acid

where $[X]=$ sulfate or fluoride.

The uranium concentration was determined by complexing it with ammonium thiocyanate and measuring the absorption at $365 \mathrm{~nm}$ by a UV spectrophotometer type of the Spectronic 601 from Bausch\&Lomb Co.

\section{Results \& discussions}

3.1 Effect of the amine concentration on fluoride and sulfate extraction

The effect of the amine concentration was investigated by extraction fluoride and sulfate from wet phosphoric acid with different (tributylamin, trioctylamin, tridodecylamin) under the same experimental conditions $\left(\mathrm{T}=25^{0} \mathrm{C}, \mathrm{O} / \mathrm{A}=1, \mathrm{P}_{2} \mathrm{O}_{5}=29 \%\right.$ $w t)$. The concentration of the amine was varied from 0.1 to 0.5 $\mathrm{mol} / \mathrm{l}$ in kerosene. The results are plotted in Fig. 1 in the form of the sulfate extraction yield versus the concentration of the amine and in Fig. 2 in the form of the fluoride extraction yield versus the concentration of the amine. The results show that the sulfate and fluoride extraction yields increase rapidly by an increase in the amine concentration for the three above solvents according to the following: tributylamin $<$ trioctylamin $<$ tridodecylamin. Ease of separation of the two phases decreases significantly with an increase in the amine concentration. A compromise should be made between ease of separation and extraction efficiency. So, experiments were further carried out on $0.3 \mathrm{~mol} / \mathrm{l}$ amine in kerosene.
- butyl $\square$ octyl $\Delta$ dodecyl

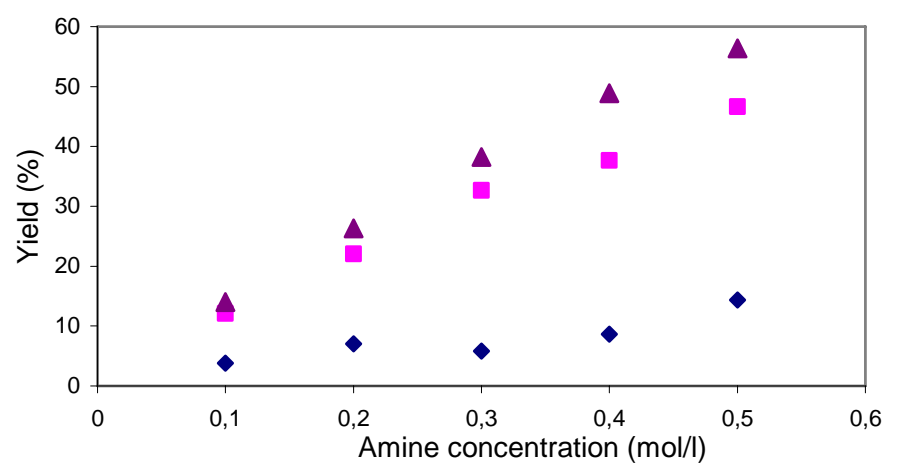

Fig. 1. The effect of amine concentration on fluoride extraction

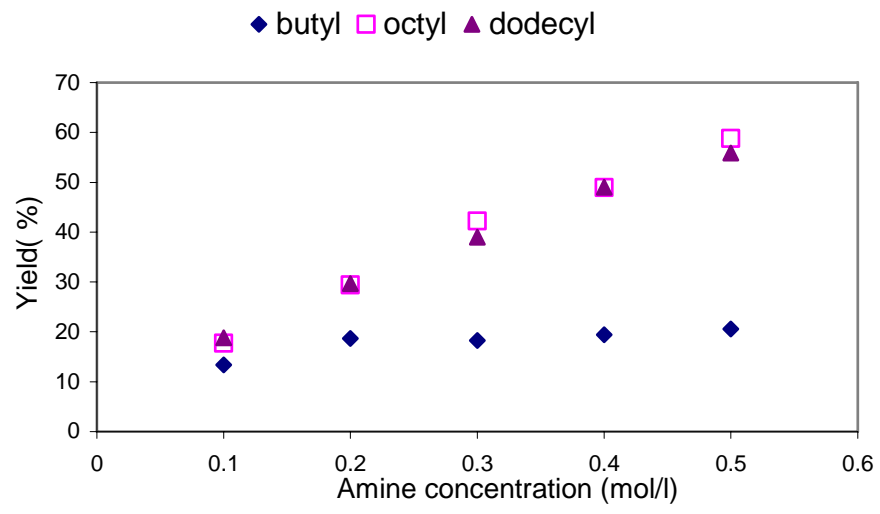

Fig. 2. The effect of amine concentration on sulfate extraction

\subsection{Effect of temperature on fluoride and sulfate extraction}

The effect of temperature was investigated by extracting fluoride and sulfate from $29 \%$ wt. $\mathrm{P}_{2} \mathrm{O}_{5}$ wet phosphoric acid by the three above tertiary amines with $0.3 \mathrm{~mol} / \mathrm{l}$ concentration using a phase ratio $\mathrm{O} / \mathrm{A}=1$ but varying the temperature from 25 to $55^{0} \mathrm{C}$. The results are plotted in Figs. 3, 4 in the form of $\mathrm{Y} \%$ versus $\mathrm{T}$ ${ }^{0} \mathrm{C}$. The results show that the fluoride extraction yield increase by an increase in the temperature for trioctylamin and tridodecylamin only and the temperature has a slight effect on the sulfate extraction yield for the three above tertiary amines and fluoride extraction yield for tributylamin. Therefore it is usual practice to carry out the extraction at room temperature.

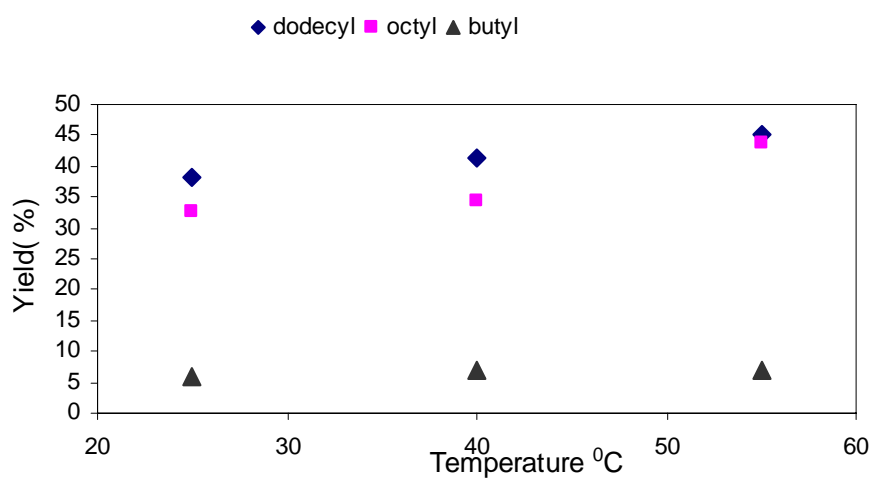

Fig. 3. The effect of temperature on fluoride extraction 


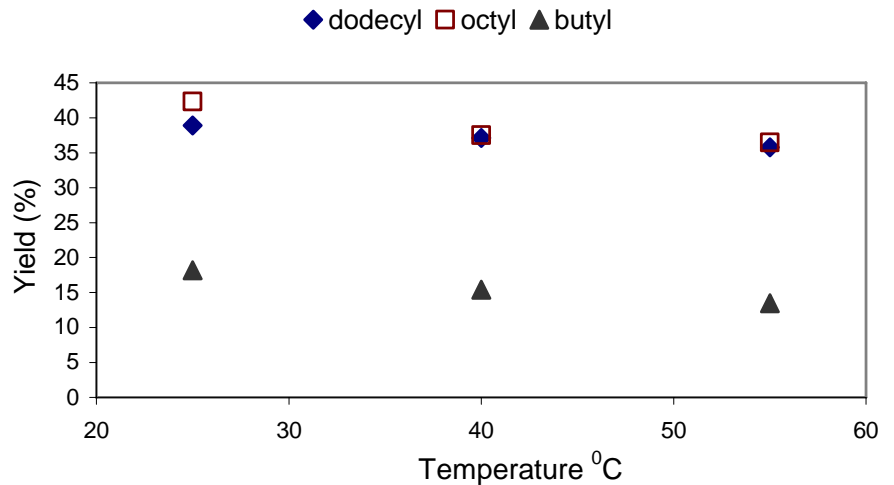

Fig. 4. The effect of temperature on sulfate extraction

\subsection{Determination of the fluoride and sulfate extraction isotherms}

The extraction isotherms of the fluoride and sulfate with tridodecylamin from wet phosphoric acid were determined. The extraction was carried out at $\left(\mathrm{T}=25^{\circ} \mathrm{C}, \mathrm{P}_{2} \mathrm{O}_{5}=29 \% \mathrm{wt}\right.$, [tridodecylamin $]=0.3 \mathrm{~mol} / \mathrm{l})$. The results are shown in Figs. ??, 6 where fluoride or sulfate in the solvent is plotted versus fluoride or sulfate in the raffinate.

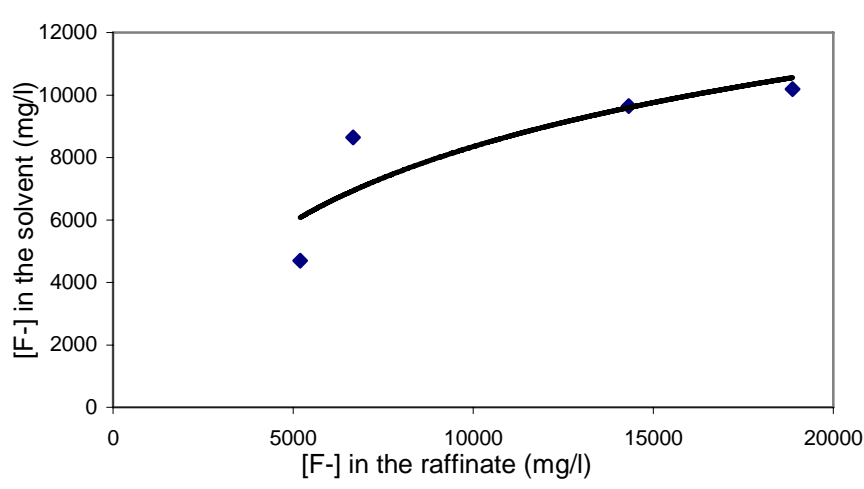

Fig. 5. Fluoride extraction isotherm

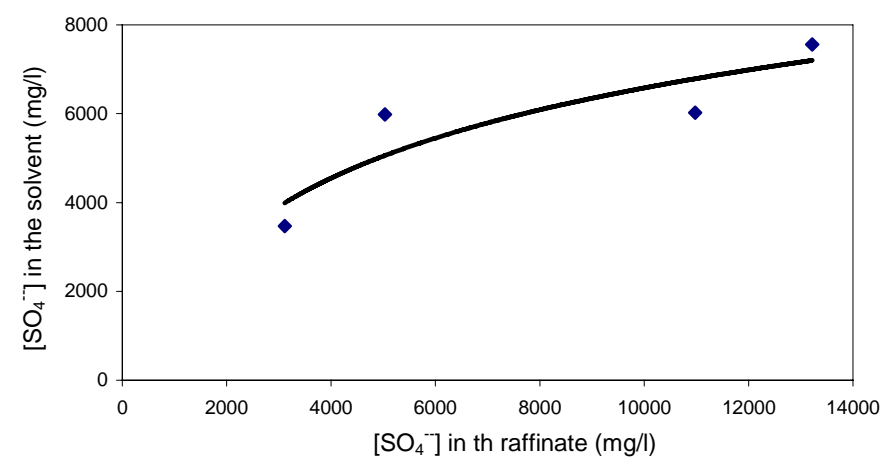

Fig. 6. Sulfate extraction isotherm

3.4 Effect of the extraction by tridodecylamin on the acid specification

The effect of the fluoride and sulfate extraction from wet phosphoric acid by $0.25 \mathrm{~mol} / 1$ tridodecylamin in kerosene on the acid specification was studied using phase ratio $\mathrm{O} / \mathrm{A}=1$ at $25{ }^{0} \mathrm{C}$. The results are represented by Table 1 . The results show that the fluoride and sulfate extraction from wet phosphoric acid has no effect on the density and concentration of the acid and a slight effect on the vanadium and uranium concentration in the acid.

Tab. 1. Shows the effect of extraction on the acid specification

\begin{tabular}{|c|c|c|}
\hline Element & Feed acid specification & Raffinate specification \\
\hline Density(Kg/l) & 1.28 & 1.28 \\
\hline $\mathrm{P}_{2} \mathrm{O}_{5} \% w t$ & 29 & 29 \\
\hline $\mathrm{F}^{-} \mathrm{mg} / \mathrm{l}$ & 9642 & 23965 \\
\hline $\mathrm{Cl}^{-} \mathrm{mg} / \mathrm{l}$ & 265 & 1377 \\
\hline $\mathrm{SO}_{4}^{--} \mathrm{mg} / \mathrm{l}$ & 10976 & 17000 \\
\hline V mg/l & 85 & 89 \\
\hline U mg/l & 64 & 65 \\
\hline
\end{tabular}

\section{Conclusions}

The previous results show that :

1 Sulfate and fluoride extraction yields increase rapidly by an increase in the amine concentration and the tridodecylamin in kerosene has the highest extraction yield.

2 The extraction yield increases by an increase in the amine concentration and the ease of phase separation decreases by an increase in the amine concentration. So, the concentration of $0.25 \mathrm{~mol} / \mathrm{l}$ tridodecylamin in kerosene was found to be the best as a result of the trade-off between the extraction yield and the ease of phase separation.

3 The temperature has a positive effect on fluoride extraction for trioctylamin and tridodecylamin and a slight effect on the sulfate extraction for the three tertiary amines and on the fluoride extraction for tributylamin.

4 The extraction has no effect on the phosphoric acid specification and a slight effect on the vanadium and uranium concentration in the acid

\section{References}

1 Baidoun R, AbuHillal J, Allaf AW, Effective reduction of fluorine content in Syria commercial phosphoric acid using silica-gel under three different conditions, Afinidad 58 (2001), no. 493, 196-209.

2 Wahoud A, Shino O, Khorfan S, Investigation of the synergistic of etheric compounds on the extraction of $\mathrm{H}_{3} \mathrm{PO}_{4}$ from Syrian wet phosphoric acid by TBP, Afinidad 61 (2004), no. 509, 39-42.

3 Aharon E, Klara H, Avraham B, A process for defluorination and purification of wet process phosphoric acids containing high Al concentrations, Solvent Extraction and Ion Exchange 2 (1984), no. 4-5, 677-697.

4 Ruiz F, Marcilla A, Martinez D, Purification of wet process phosphoric acid by extraction with 3-Pentanone. Study of the impurities distribution, Solvent Extraction and Ion Exchange 11 (1993), no. 3, 455-467. Comment on the purification behavior of different solvents.

5 Habashi F, Awadalla F, The removal of fluorine from wet process phosphoric acid, Separation Science and Technology 18 (1983), no. 5, 485-491, DOI 10.1080/01496398308060289.

6 Purification of wet phosphoric acid with solvent extraction, 1, 1992. MEAB Mettallextractio AB. 
7 Canadian patent database: Solvent extraction of a halide from an aqueous sulphate solution.

8 Aharon E, Klara H, Avraham B, Wet process phosphoric acid defluorination by amine-based extractants, Solvent Extraction and Ion Exchange 2 (1984), no. 4-5, 659-675.

9 Abdulbaki M, Shino $\mathbf{0}$, Removing the cadium, arsenic and sulfate ions from wet process phosphoric acid, Periodica Polytechnica Chem. Eng. 48 (2004), no. 1, 63-71.

10 Abdulbake M, Shino O, Synergistic effect of some alcohols on the extraction of $\mathrm{H}_{3} \mathrm{PO}_{4}$ from Syrian wet phosphoric acid by TBP, Periodica Polytechnica Chem. Eng. 51 (2007), no. 1, 3-6, DOI 10.3311/pp.ch.2007-1.01.

11 Khorfan S, Shino O, Wahoud A, Extraction of $\mathrm{H}_{3} \mathrm{PO}_{4}$ from wet phosphoric acid by $n C 4-n C 7$ alcohols, Periodica Polytechnica Chem. Eng. 45 (2001), no. 2, 139-148.

12 Moussa Alibrahim, Extraction of phosphoric acid from various aqueous solutions using tributyl phosphate (TBP), Periodica Polytechnica Chem. Eng. 51 (2007), no. 1, 39-42, DOI 10.3311/pp.ch.2007-1.07. 